\title{
Designing a Residential Resort in Mexico: Third-Year Community Design Lab, Summer 2007
}

VICENTE DEL RIO

Vicente del Rio, Ph.D.

is a professor at $\mathrm{Cal}$ Poly's City and Regional Planning Department and FOCUS managing editor.

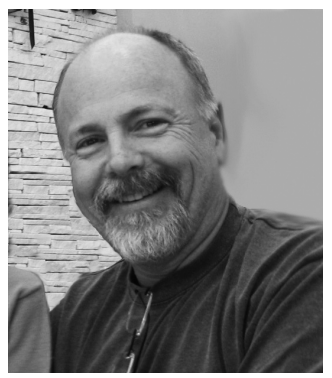

${ }^{1}$ Architects Robert Richmond and David Vizcarra, and planner William Howard.

Figure 1 Project site at Bahia de Banderas, showing the estuary and the pueblo on the right side.

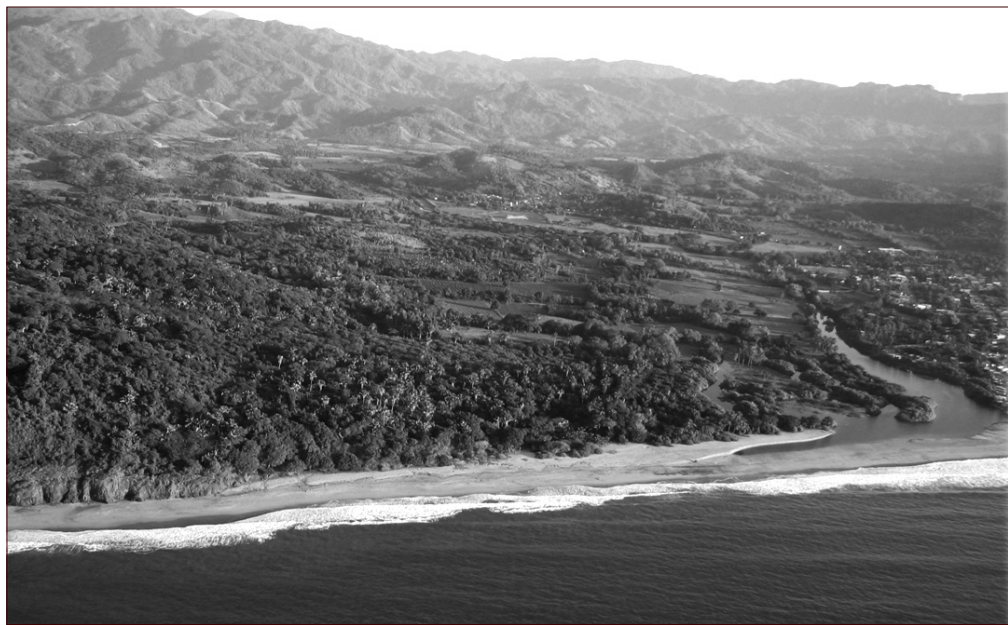

In the summer of 2007, a third-year design class was challenged by a real project and real clients: to plan and design a residential resort in the costal Mexican pueblo of Lo de Marco, in the beautiful Bahia de Banderas, on the cost of Nayarit just north of Puerto Vallarta. Acting as if they were consultants, the students responded extremely well to the challenge and did a great job of creating unique and feasible ideas.

In the summer 2007, the CRP department offered a third-year urban design studio (CRP 341: Community Design Lab), which turned out to be an excellent exercise for the students involved, and also a lot of fun. As a professional, I had recently been involved in some consulting with a local San Luis Obispo firm that was submitting a development proposal for a small residential resort and hotel in Bahia de Banderas, state of Nayarit, Mexico. During the previous spring, I had visited the area with the firm's representatives, and we had made a brief development proposal and concept diagram. While we were waiting for a response from the Nayarit state government, I got the firm interested in having my studio take on this project during the summer. The class would take the brief and diagram as a start, and develop design alternatives, helping the firm to "think outside the box," and presenting fresh ideas. It was a good fit with Cal Poly's "learn-by-doing" philosophy and the CRP Department's "hands-on" approach, with a real client and a real project. It also presented the students with a totally new task which occurs often in real-life situations: to get engaged in a project within a context you do not know much about and you cannot visit in person.

The project site is located in Bahia de Banderas, north of Puerto Vallarta, one of Mexico's most famous coastal resorts on the Pacific coast. Also close is Nuevo Vallarta, an expansion of Puerto Vallarta to the north, where new expensive resorts and multimillion-dollar residential developments attract rich vacationers and retirees. Bahia de Banderas is in he state of Nayarit's costal region, which is the object of intense governmental master planning in order to conciliate tourism, development and the preservation of natural resources. The open bay, a beach of white sands, a mountain range, and a river estuary limit the site. Just across this estuary is the pueblo of Lo de Marco, a small village originally settled by a fishing community. Although the beach, the spectacular landscape, and the pueblo were attracting an increasing number of tourists, Lo de Marco's historic and vernacular architecture and slow pace of life were perfectly preserved.

Besides having to respond to a site and context they were not familiar with, the students faced other challenges. The project site was extended to the costal highway just south of the pueblo, totalizing almost 250 acres (the original client's site was approximately 90 acres). Students had to expand the original program, incorporate other elements of their choice in the resort planning, and decide for the phasing of the development. The river estuary and its riparian vegetation were a preservation area, and 
had to be integrated to the project, and the existing topography and landscape had to be respected as much as possible. The project had to be integrated to the pueblo not only morphologically but also socially, culturally, and economically. It was within the interest of all stakeholders (clients, Mexican government, and local community) that the resort is respectful of the local social, cultural, and environmental contexts, and that it provides the area with a positive sustainable development with positive reflections for all. Students adopted the clients' name and vision for the resort: Serenidad de Lo de Marco : "an international-level quality destination resort that will respond to the site's and the region's development potential, as well as to the coastal tourist-oriented efforts of the Estado de Nayarit. Its unique planning and design approach will be responsive to the local eco-system, to the beauty of the natural landscape, and to the economic, social, and cultural needs of the community of Lo de Marcos."

Thus, in this studio, the students faced a "real situation" and encountered the same problems, constraints, limitations, and frustrations as in dealing with a real project: limited time and information. They were "hired" as "consultants" to develop a concept plan in a context they had to develop an understanding of on all possible levels: cultural, political, environmental, social, regulatory, market, etc. Programming and design development became two strongly complementary phases in their work. Much like international consultants, they dealt with a big challenge: they could not visit the site and had limited time and access to information. In the end, the class was very successful and the students were able to come up with extremely interesting and feasible plans, making the clients happy with their performance and helping them to think "outside the box." The class had 19 students divided into 6 design teams. The following images and descriptions are excerpts from two final reports (some reports had up to 60 pages $11 \times 17$ " format!) from the projects that received the highest rankings from the clients. The clients were happy with the results because they were provided with several seriously inspiring design approaches and ideas. Presently, they are waiting for a final response from the Nayarit state government to their development proposal, and then, hopefully, they will be able to consider developing some of the class' ideas.

\section{Project 1: Ryan Brough, Nadege Dubuisson, Cal Garcia, and Chris Gomez Ortigoza}

The concept for the area given to us by the architects called for an original design leading to our vision statement for Serenidad en Lo De Marco. Our's should be a unique resort, offering a cultural experience integrated to the town while providing the modern amenities of an international high-quality resort destination that coexists with the natural elements. Creating a "unique" resort is a difficult task, and there are numerous resorts scattered along the Pacific Coast of Mexico, all attempting to be unique. Many rely on golf courses as their main draw, and it became clear to us that a resort of our size could not properly accommodate a professional golf course; moreover, such a feature would also have high environmental impacts. We decided on a high-quality equestrian center and multiple recreational activities linked to the beautiful natural environment.

Our design for Serenidad en Lo de Marco integrates key elements of open space: recreation, residential, and agricultural use, bringing together two different worlds of the new and the old. Adapted to the natural terrain, site planning incorporates a clearly defined structure and nodes strategically placed throughout the project to serve different purposes while interacting with one another. The circulation pattern allows for an easy mobility between the three different development phases; connectivity provides for the site to work as a whole. The three development phases are integrated but can stand alone, and will culminate in a unique international residential resort. 

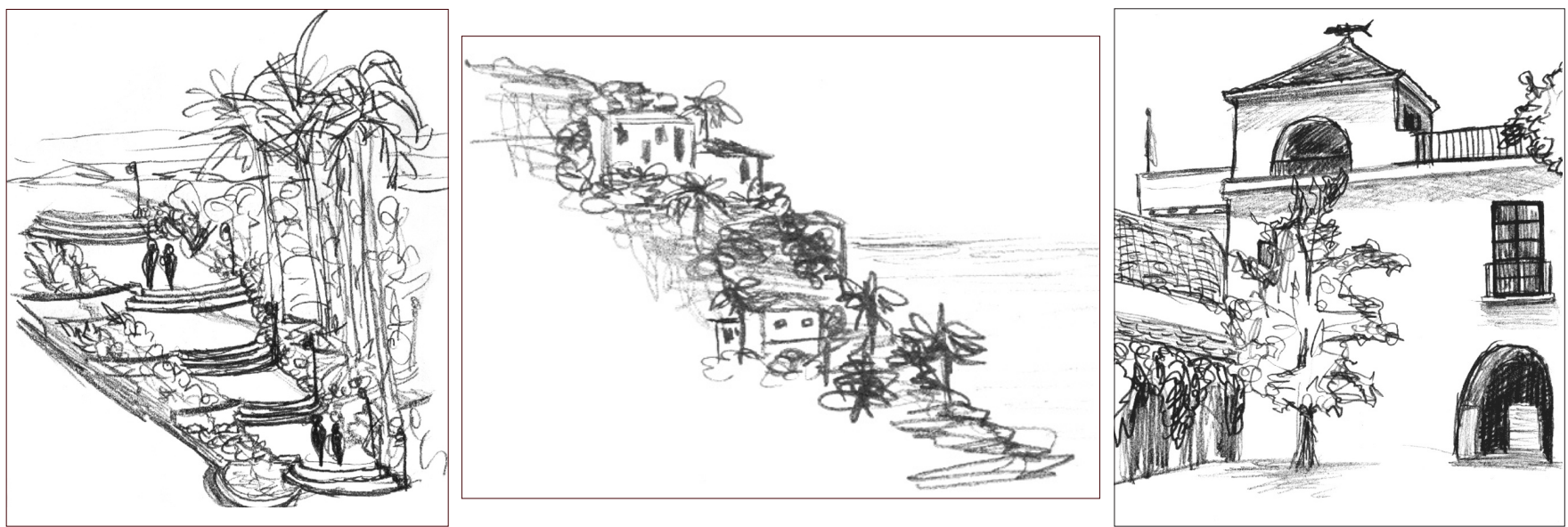

Figures 2, 3 \& 4

Team 1: concept sketches of landscaped steps, the new church and plaza, and some of the "casitas" units at the resort.

Sketches by Nadege Dubuisson.

Figure 5

Team 1: SketchUp model showing Phases $1 A$ and $B$.
Phase $1 \mathrm{~A}$ will comprise the northwestern part of the site, in the original smaller project site. A clear gateway will mark the entrance from the village of Lo de Marcos. As more land is acquired and other phases developed, the main circulation patterns will originate from a new off-ramp directly connected to Mex-200, the costal highway. This first phase will include a 250-room luxury hotel with six adjacent bungalows that are accessible via golf carts. Pedestrian space will also exist throughout the site with direct beach access from the hotel area. In order to limit auto circulation, a 60,000-sqf two-level parking structure with valet parking will be available. Together with other amenities to guests and visitors, a tennis club will serve as the main recreation in Phase 1A. Also included is a 12,500-sqf education center and boardwalk along the estuary and lagoon, providing opportunities to visitors and Lo de Marco residents to interact and learn from the surrounding environment. Open space is preserved and enhanced throughout this phase in order to retain the natural character and view sheds that make this site so unique.

Phase 1B comprises most of the northern part of the project site. Access will follow directly from the road established during Phase $1 \mathrm{~A}$, leading to a meandering road up the hill to the 28 townhomes, 16 luxury estates, and ending at a 3,000-sqf spa and a 7,000-sqf restaurant with ocean views. The luxury estates are sited to explore the amazing views and respond to the natural setting, while still preserving a sense of privacy. A system of open spaces and bio-swales will create natural barriers

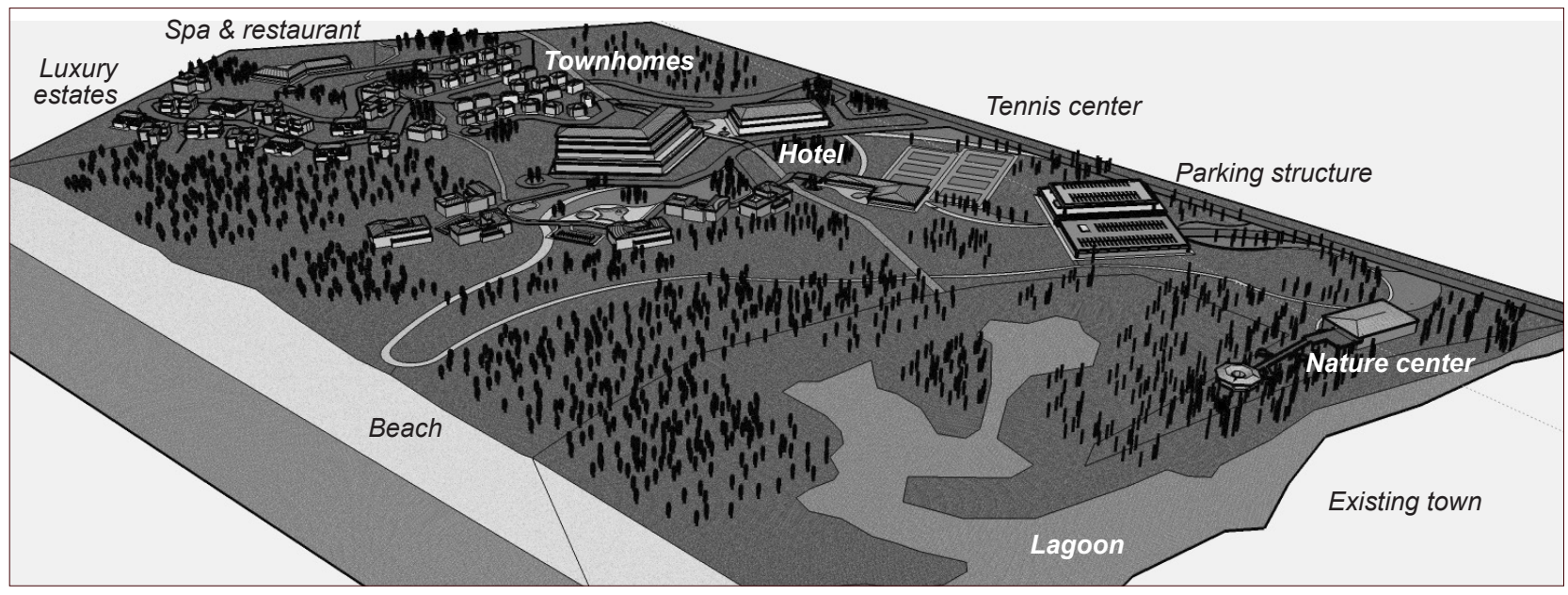


between the estates and the hillside townhouses which will still hold their own view sheds even if in a denser setting. At the pinnacle of the hill are a luxury spa and a top quality restaurant with breath taking views, which will serve cuisine using locally-grown produce. Next to the spa, 5 honeymoon suites are designed in a way to truly offer a romantic natural feel and a greater sense of privacy. A large portion of this phase has been left to be open space/preserved land because of the natural topography.

Phase 2 occupied the central portion of our project site in a relatively flat area bordered by the river. It will be access from Phase $1 \mathrm{~A}$ until Phase 3 is developed. This phase comprises elements integrated in a sustainable relationship. It will focus on a state-of-the art equestrian center with 24 horse stalls, 36 equestrian estates, and a small organic agricultural field that will provide produce for the resort. This flat area provides for optimal sun exposure and the opportunity for energy conservation through solar panels. Also in this phase are soccer facilities that will integrate the life of the resort with the neighboring pueblo. Phase 3 encompasses the southernmost part of the project site, bordered at the

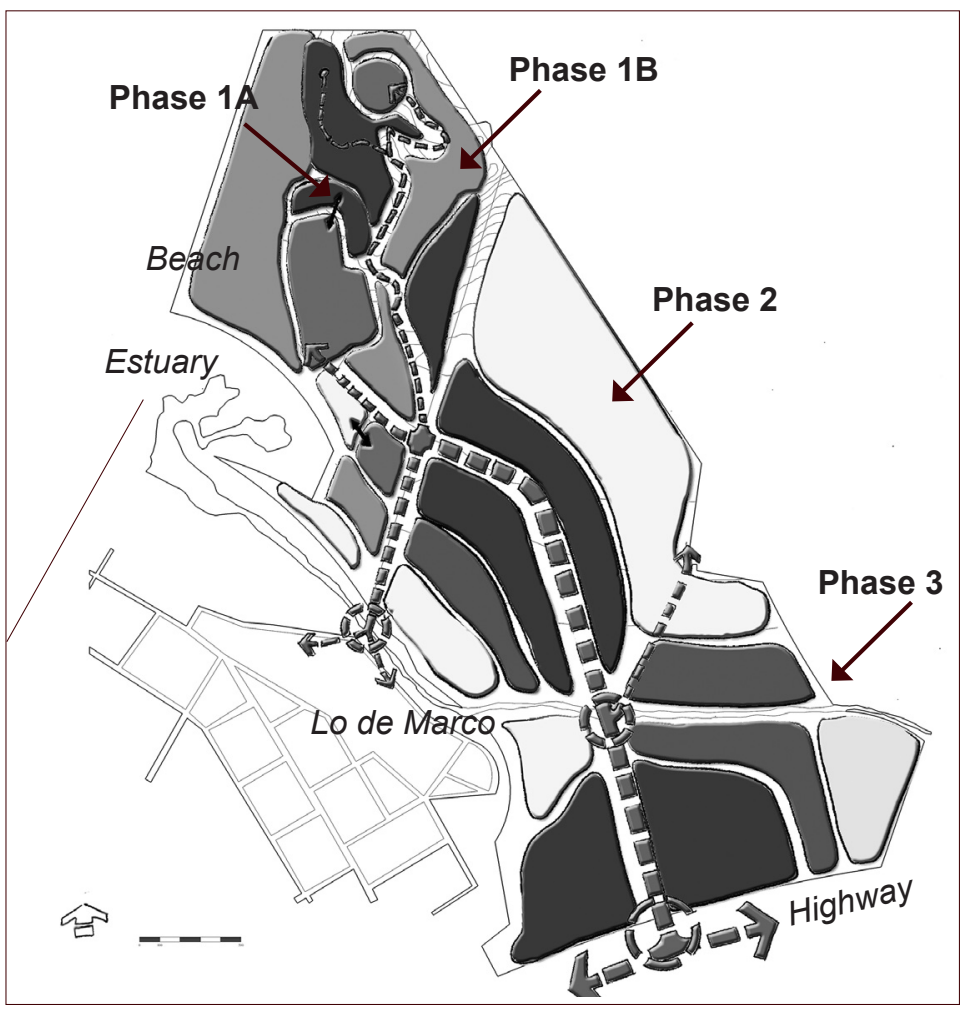

North by a river and South by the highway Mex-200. It includes a main entrance into the resort that would alleviate traffic through Lo de Marcos, a plaza with a small church and a retail center around it, together with affordable housing for workers in the resort and other patrons. In this location, the water and sewage treatment plant would be buffered from views by abundant landscaping.

\section{Project 2: Nancy Cole, Eric Anaya, and Lorie Ingam}

When developing the Monteon [eco] Resort Development Plan, ecotourism is the theoretical framework underlying the design decisions, 'focusing on the local culture, wilderness adventures, volunteering, and learning new ways to live on the planet.' We asked ourselves how to develop on the site in such a way that has the least amount of impact on the environment, optimizing local resources (including material, energy, and water resources), and maximizing the benefit for the Lo de Marcos population. The visionary process included the development of five major design criteria: (a) land use, (b) connectivity, (c) green building, (d) architectural style, and (e) landscape conservation.

Our eco-friendly design concepts incorporate the utilization of local materials and skills to reflect the native architectural typologies, designing buildings that respond to the natural climate and viewsheds of the site, and utilizing local flora for landscaping. Phase One centers around developing visitors' sense of nature and place. Outdoor activities include hikes, kayaking, other sports and guided nature tours of the region and the nearby village of Lo de Marcos, and encouraging patronage of the farmers' market. The organic farm beyond the south edge of Phase One provides local, organic agriculture for the resort, while providing jobs to the inhabitants of Lo de Marco. The agricultural site is selected based on its stream area, and the low slope. Indoor activities include a workshop space,
Figure 6

Team 1: Concept diagram and phasing. 


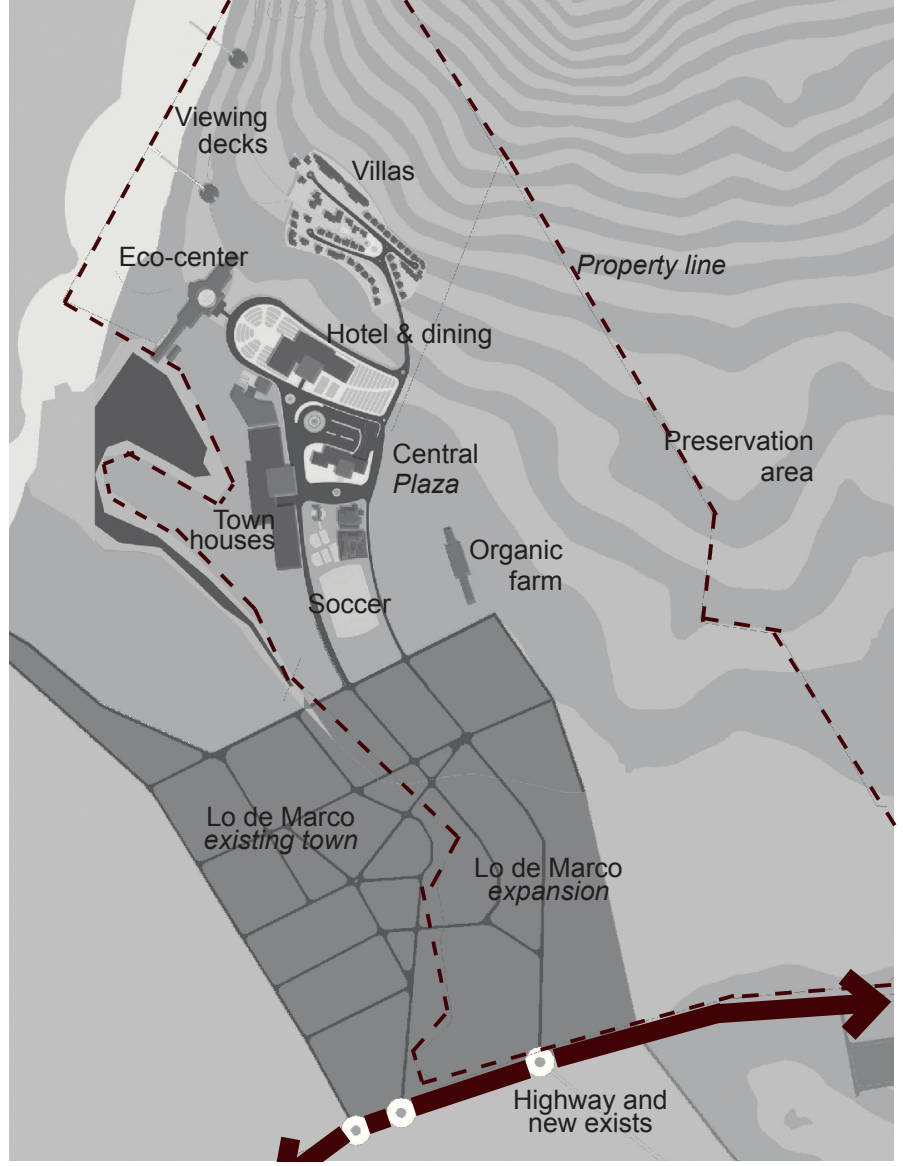

Figures $7 \& 8$

Team 2: Concept diagram of complete project, and 3D Model of the first phase. ballroom, a library, a full conservatory, and a multi-purpose room in which guests can host large parties. Approximately 50 percent of the first phase of the site will be preserved.

Since the beginning of the quarter, we decided that the resort would be an eco-resort, and, after receiving great feedback from the clients and guest speakers, we expanded on our idea further. To entice people to come to our facility, our project would be a high-tech ecological resort, which means that in our design we will be using the latest and greatest ecological technology available while providing appealing eco-activities to our guests. We incorporate eco-design and all solutions consider resources that are natural, so natural that they can be recycled to the earth without causing damage. Through this cycle we hope that it will repeat the natural regularity of living things. In our project we would also like to include methods such as sustainability and green building. The hillside villas, for instance, are long and thin to dissipate the heat, with internal courtyards that set up patterns of crossventilation and increase the ratio of surface area to volume. Deep overhanging eaves are provided for essential weather protection for exterior surfaces. Villas will be designed to respond to the natural micro- and macroclimate of the area to maximize energy efficiency, and will use photovoltaic systems. The design will involve as little disruption as possible and composting waste systems will be installed.

Our central "plaza," which, in Mexican culture, is where most social activities are located, will be an educational center. Here locals and tourists can learn about the numerous features of the resort. They can learn about all the eco technology used on site such as energy efficiency, material

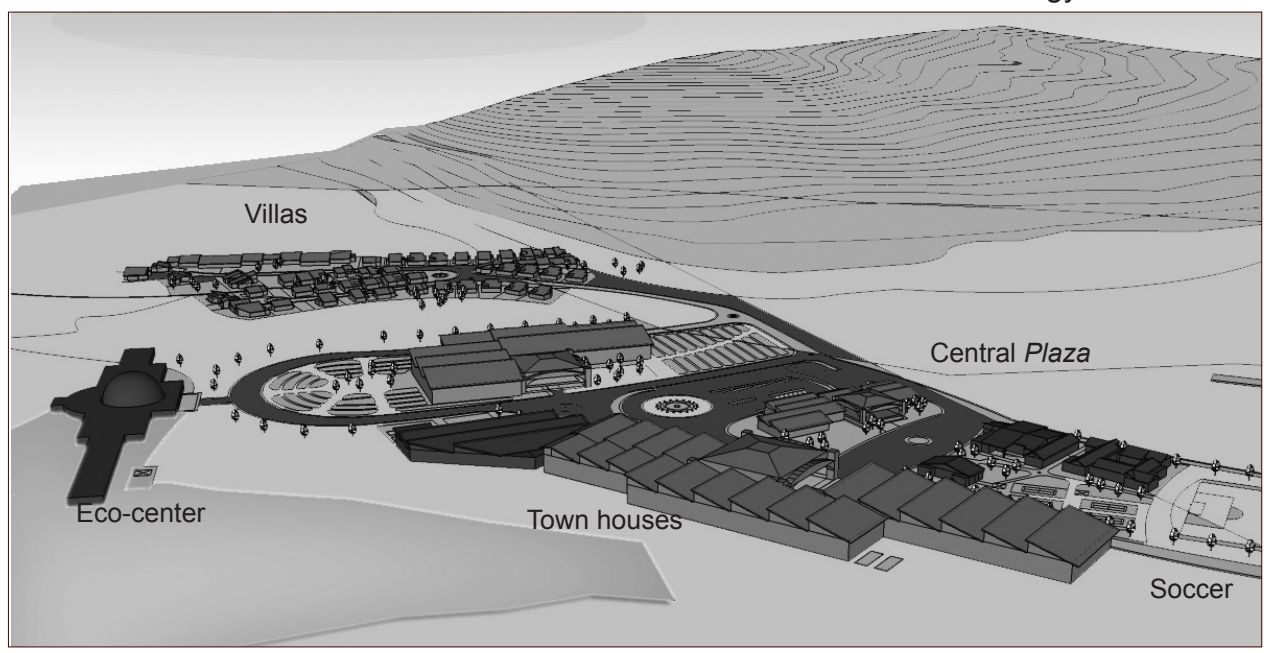
choice and use, site impact, water use and efficiency, longevity and flexibility. Also, Mexico has such a rich, artistic heritage of song, dance, architecture, art, and artifacts, which are colorful and unique. These are all elements that can be used to support the creation of a sense of a place. Tourists may learn about the town of Lo de Marcos, the culture of the town, or of Mexico in general. Since our resort is meant to be one of the top eco tourist resorts, we would offer workshops focusing 
on sustainable practices: green building, energy efficiency, straw bale building, etc. Our target demographics are mainly professionals that desire to learn more about eco design in a beautiful tropical setting, so we feel it would be appropriate to include workshops for those professionals. For non-professionals, they would learn through the educational center as well as the educational/ environmental tours or they may just relax and enjoy the natural environment.
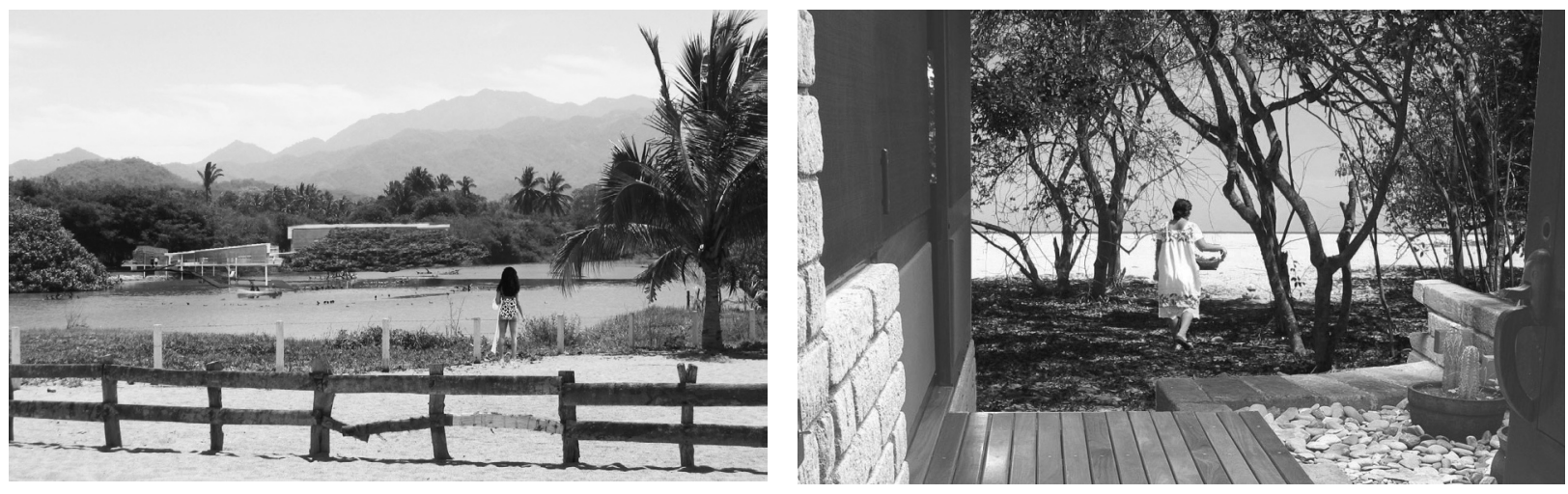

Figures 8 \& 9

Team 2: Computer simulations of the design concepts inserted into photos of the area. On the left, the lagoon and the Eco-Center. On the right, the beach views from the villas. 